\title{
Carbon molecular sieve structure development and membrane performance relationships
}

\author{
Meha Rungta†, Graham B. Wenz†, Chen Zhang, Liren Xu, Wulin Qiu, Jason S. Adams, \\ William J. Koros* \\ School of Chemical \& Biomolecular Engineering, Georgia Institute of Technology, \\ 311 Ferst Drive, Atlanta GA 30332, USA
}

\begin{abstract}
Characterization techniques beyond microscopy, scattering and spectroscopy approaches are needed to understand and improve sub-angstrom discrimination between penetrants in carbon molecular sieve (CMS) membranes. Here we use a method based on molecular scale gas diffusion probes to understand relevant membrane properties at the required level of detail. We further use this method to consider hypotheses about the evolution of structure responsible for fundamental properties of CMS materials derived from a high performance CMS precursor polymer, 6FDA:BPDA-DAM. While 6FDA:BPDA-DAM derived CMS membranes display a $\sim 230 \%$ improvement in $\mathrm{CO}_{2}$ permeability when compared to Matrimid ${ }^{\circledR}$ derived $\mathrm{CMS}$ formed under the same conditions, the diffusional selectivity for these two materials are very similar at 35 and 38.5, respectively. These results indicate a non-trivial connection between CMS precursor material structure and resulting performance. Linking hypotheses about structural changes likely to occur during pyrolysis with the probe data provides insights regarding transformation of the random coil polyimide into ultra-rigid CMS, with exquisite size and shape diffusion selectivity. The results provide a framework for understanding and tuning properties of this special class of materials with important technological advantages in energy-intensive gas separations.
\end{abstract}

"Corresponding author. Tel: +1 404385 2845. Email: wjk@ chbe.gatech.edu (W. J. Koros)

†M.R. and G.B.W contributed equally 


\section{Introduction and Background}

Carbon molecular sieve (CMS) materials (1-6) surpass the permeability versus selectivity "upper bound" trade-off (7-10) of solution-processable polymers and provide a platform for creating advanced membranes. It is generally accepted that CMS transport properties rely upon a slit-like pore structure consisting of a distribution of larger $(\sim 7-20 \AA)$ micropores connected by smaller $(<7 \AA)$ ultramicropore windows $(3,11-13)$. This fact notwithstanding, understanding the evolution of precursor semi-flexible polymers into final CMS structures is at an early stage. Figure 1a (i \& ii) represent the CMS pore structure and bimodal distribution comprising micropores and ultramicropores. Figure $1 \mathrm{~b}$ is a popular representation of a CMS material derived from a hydrocarbon precursor but it also provides a starting point for discussion of more complex CMS materials derived from polyimide precursors in our work, such as shown in Fig. 2.

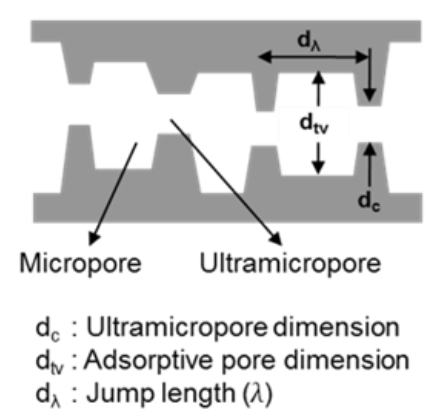

(i)

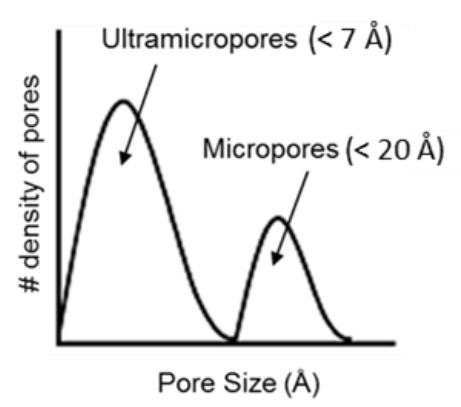

(ii)

Figure 1a. CMS (i) Ideal "slit-like" pore structure and (ii) Bimodal distribution of pores (1).

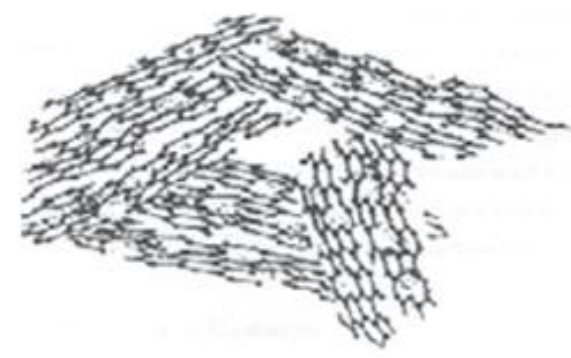

Figure 1b. Turbostratic carbon structure believed to represent some CMS materials (14). 


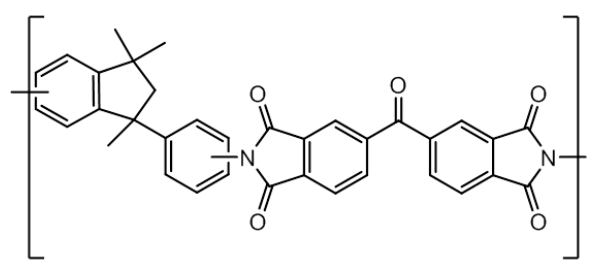

Matrimid $^{\circledR}$ (BTDA-DAPI)

BTDA: 3,3'-4,4'-benzophenone tetracarboxylic dianhydride

DAPI: 5(6)-amino-1-(4'-aminophenyl)-1,3-trimethylindane

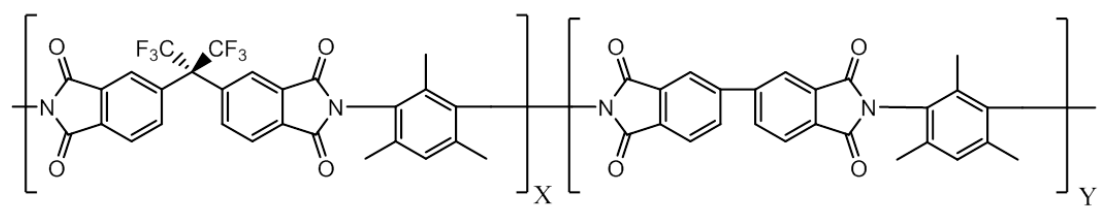

6FDA:BPDA-DAM $(\mathrm{X}=1, \mathrm{Y}=1)$

6FDA: 4,4'-(hexafluoroisopropylidene) diphthalic anhydride

BPDA: 3,3'-4,4'-biphenyl tetracarboxylic dianhydride

DAM: 2,4,6-trimethyl-1,3-phenylene diamine

Figure 2. Chemical structure of semi-flexible precursor polyimides Matrimid $^{\circledR}$ and 6FDA:BPDA-DAM(1:1).

Making a connection between the representations of the bimodal distribution of pores in Fig. 1a and a more chemically-relevant structure such as that in Fig. 1b is desirable-but challenging. It is reasonable to connect these two representations by attributing ultramicropores to defects within the plates shown in Fig. 1b, while attributing the micropores to the spaces between the plates. Of course, the details of the plate structure in such a picture will be different in a simpler hydrocarbon versus a polyimide derived CMS. Unlike oxygen-containing cellulosic and purely hydrocarbon precursors, the presence of fluorine and nitrogen in the polymer backbone introduces additional factors affecting the ultimate properties of the final CMS versus the case in Fig. 1b. Moreover, differences will exist even between CMS derived from different precursor polyimides $(1,15,16)$; however, the general concepts and features should be similar, as is considered later in this discussion. 
Previous work on CMS materials derived from Matrimid ${ }^{\circledR}$ and similar aromatic polyimide precursors noted the difficulties in using traditional characterization techniques, due to the amorphous nature of these materials (17-21). Recent work on more complex 6FDA-based polyimide precursors further highlighted the disconnect between precursor physical properties and the resulting CMS materials. This recent work documented the lack of direct physical connection between free volume and x-ray "d-spacings" of polymer precursors and corresponding properties of CMS (22). Considering these previous discussions, it is evident that this lack of a simple connection between the random coil precursor and the generally accepted slit-like structure of the final CMS, reminiscent to Fig. 1, needs to be addressed $(1,3)$. Establishing such a connection is critical to the advancement of the fundamental understanding of CMS materials. The current work aims to establish this important connection by discussing similarities and differences that arise from Matrimid ${ }^{\circledR}$ and 6FDA:BDPA-DAM derived CMS materials.

\section{Transport Theory}

Gas transport in CMS can be described using the sorption-diffusion model represented by Eq. 1, where, $\mathrm{P}_{\mathrm{A}}$ is the permeability of component $\mathrm{A}, \overline{\mathrm{D}}_{\mathrm{A}}$ and $\overline{\mathbb{S}}_{\mathrm{A}}$ are the average diffusion and sorption coefficients respectively. Permeability is measured in Barrer, where

$$
\begin{gathered}
1 \text { Barrer }=1 \times 10^{-10}\left[(\mathrm{cc}(\mathrm{STP}) \mathrm{cm}) /\left(\mathrm{cm}^{2} \cdot \mathrm{s} \cdot \mathrm{cmHg}\right)\right]=3.34 \times 10^{-16}\left[(\mathrm{~mol}) /\left(\mathrm{m}^{2} \cdot \mathrm{s} \cdot \mathrm{Pa}\right)\right] . \\
\mathrm{P}_{\mathrm{A}}=\overline{\mathrm{D}}_{\mathrm{A}} \overline{\mathbb{S}}_{\mathrm{A}}
\end{gathered}
$$

Gas molecules sorb into the CMS micropore sites and transport through the membrane by hopping from site to site, driven by a concentration gradient, which reflects the local chemical potential gradient of that penetrant. The critical ultramicropore windows restrict diffusion, allowing effective discrimination between similar sized gas molecules via a molecular sieving 
effect $(23,24)$. These ultramicropore sites are the key to tailoring the gas separation performance of CMS produced under different conditions. Sorption in CMS can be characterized by a Langmuir isotherm (Eq. 2), where $\mathrm{C}_{\mathrm{HA}}^{\prime}$ is the Langmuir saturation constant, $\mathrm{b}_{\mathrm{A}}$ is the Langmuir affinity constant, and $\mathrm{p}_{\mathrm{A}}$ is the partial pressure of component A, respectively $(25,26)$.

$$
\mathrm{C}_{\mathrm{A}}=\mathrm{C}_{\mathrm{HA}}=\frac{\mathrm{C}_{\mathrm{HA}}^{\prime} \mathrm{b}_{\mathrm{A}} \mathrm{p}_{\mathrm{A}}}{1+\mathrm{b}_{\mathrm{A}} \mathrm{p}_{\mathrm{A}}}
$$

The sorption coefficient represents the concentration of gas $\left(\mathrm{C}_{\mathrm{A}}\right)$ taken up by the membrane material at a given partial pressure $\left(\mathrm{p}_{\mathrm{A}}\right)$ at equilibrium,

$$
\overline{\mathbb{S}}_{\mathrm{A}}=\frac{\mathrm{C}_{\mathrm{A}}}{\mathrm{p}_{\mathrm{A}}}
$$

The average transport diffusivity can then be obtained from Eq. 1 and Eq. 3 as $\overline{\mathrm{D}}_{\mathrm{A}}=\mathrm{P}_{\mathrm{A}} / \overline{\mathbb{S}}_{\mathrm{A}}$. Since the local transport (Fickian) diffusivity $\mathrm{D}_{\mathrm{A}}$ tends to be concentration dependent, it is best to characterize molecular sieving behavior based on a thermodynamically corrected (Maxwell-Stefan) diffusivity $\bigoplus_{\mathrm{A}}$ by accounting for gas loading $(25,27)$ as follows:

$$
\mathrm{D}_{\mathrm{A}}=\frac{\bigoplus_{\mathrm{A}}}{1-\theta_{\mathrm{A}}}
$$

Here $\theta_{\mathrm{A}}$ is the fractional site-saturation factor, represented by

$$
\theta_{\mathrm{A}}=\frac{\mathrm{C}_{\mathrm{A}}}{\mathrm{C}_{\mathrm{HA}}^{\prime}}=\frac{\mathrm{b}_{\mathrm{A}} \mathrm{p}_{\mathrm{A}}}{1+\mathrm{b}_{\mathrm{A}} \mathrm{p}_{\mathrm{A}}}
$$

Thus, when the membrane downstream is at vacuum $\left(\mathrm{C}_{\mathrm{A}}=0\right)$, the average transport diffusivity $\left(\bar{D}_{A}\right)$ can be correlated to the corrected diffusivity $\left(\bigoplus_{A}\right)$ and fractional site saturation $\left(\theta_{\mathrm{A}}\right)$ as follows: 


$$
\overline{\mathrm{D}}_{\mathrm{A}}=\frac{\int_{\mathrm{C}_{\mathrm{A}}}^{0} \mathrm{D}_{\mathrm{A}} \mathrm{dC}_{\mathrm{A}}}{\int_{\mathrm{C}_{\mathrm{A}}}^{0} \mathrm{dC}_{\mathrm{A}}}=\frac{\bigoplus_{\mathrm{A}}}{\theta_{\mathrm{A}}} \ln \left(\frac{1}{1-\theta_{\mathrm{A}}}\right)
$$

A detailed derivation of the Equation 6 can be found in $(25,27,28)$.

The ideal selectivity of the membrane can be represented as

$$
\alpha_{\mathrm{A} / \mathrm{B}}=\frac{\mathrm{P}_{\mathrm{A}}}{\mathrm{P}_{\mathrm{B}}}=\left(\frac{\overline{\mathrm{D}}_{\mathrm{A}}}{\overline{\bar{D}}_{\mathrm{B}}}\right)\left(\frac{\overline{\mathbb{S}}_{\mathrm{A}}}{\overline{\bar{S}}_{\mathrm{B}}}\right)
$$

\section{Experimental}

\subsection{Pyrolysis and Characterization Protocols}

Earlier work involved pyrolysis of the commercial polyimide Matrimid $^{\circledR}$, which lacks fluorine so no $\mathrm{CF}_{3} \mathrm{H}$ or $\mathrm{HF}$ is evolved, but $\mathrm{CO}_{2}, \mathrm{CO}, \mathrm{CH}_{4}$ and $\mathrm{H}_{2}$ evolution still occurs $(18,29)$. Aromatized strands and plates resulting from Matrimid ${ }^{\circledR}$ pyrolysis, leading to an idealized CMS similar to that shown in Fig. $1 \mathrm{~b}$ will be different in detail, but similar in overall strand-like nature. In our earlier study for the Matrimid ${ }^{\circledR}$ precursor, an attractive pyrolysis temperature in ultra high purity (UHP) Argon was found to be $675{ }^{\circ} \mathrm{C}(30)$. For comparison, besides the new results we report here for the 6FDA:BPDA-DAM derived CMS we also discuss the earlier

Matrimid $^{\circledR}$ derived CMS, results from pyrolysis at $675^{\circ} \mathrm{C}$ in UHP Argon with the following heating protocol (30), viz.,

1) $50{ }^{\circ} \mathrm{C} \rightarrow 250{ }^{\circ} \mathrm{C}$ at a ramp rate of $13.3^{\circ} \mathrm{C} / \mathrm{min}$

2) $250{ }^{\circ} \mathrm{C} \rightarrow\left(\mathrm{T}_{\max }-15\right){ }^{\circ} \mathrm{C}$ at a ramp rate of $3.85{ }^{\circ} \mathrm{C} / \mathrm{min}$

3) $\left(\mathrm{T}_{\max }-15\right){ }^{\circ} \mathrm{C} \rightarrow \mathrm{T}_{\max }{ }^{\circ} \mathrm{C}$ at a ramp rate of $0.25{ }^{\circ} \mathrm{C} / \mathrm{min}$

4) Soak for 120 mins at $T_{\max }$

5) Cool naturally to room temperature under flowing UHP Argon

where, $\mathrm{T}_{\max }$ is the $675^{\circ} \mathrm{C}$ final pyrolysis temperature noted above, unless otherwise specified. 


\subsection{Gas Probes}

CMS dense films were characterized using pure gas permeation and equilibrium sorption measurements. Details of CMS fabrication, permeation and sorption experiments for feed pressures up to 100 psia have been reported previously (28). Sorption coefficients were obtained from direct sorption measurements using Eqs. 2 and 3 and average transport diffusivities were back-calculated using permeability and sorption coefficients with Eq. 1. Further, Maxwell-Stefan corrected diffusivities were calculated using Eq. 6. An extensive array of gases (Table 1), were used to gain insight into CMS performance and properties.

Table 1: Size $(\sigma)$ and critical temperature $\left(\mathrm{T}_{\mathrm{c}}\right)$ for common gases $\left(\mathrm{H}_{2}, \mathrm{CO}_{2}, \mathrm{O}_{2}, \mathrm{~N}_{2}, \mathrm{CH}_{4}\right)$ adopted from (26), noble gases (He, $\mathrm{Ne}, \mathrm{Ar}, \mathrm{Kr}, \mathrm{Xe})$ from $(31,32)$, for $\mathrm{SF}_{6}$ from $(26,31)$, with size of $\mathrm{C}_{2} \mathrm{H}_{4}$ and $\mathrm{C}_{2} \mathrm{H}_{6}$ defined based on slit-like pores using space-filling CPK models and calibrated "slits" $(17,33)$.

\begin{tabular}{|c|c|c|c|c|c|c|c|c|c|c|c|c|c|}
\hline $\mathrm{Gas}$ & $\mathrm{He}$ & $\mathrm{Ne}$ & $\mathrm{H}_{2}$ & $\mathrm{CO}_{2}$ & $\mathrm{O}_{2}$ & $\mathrm{Ar}$ & $\mathrm{N}_{2}$ & $\mathrm{Kr}$ & $\mathrm{C}_{2} \mathrm{H}_{4}$ & $\mathrm{CH}_{4}$ & $\mathrm{C}_{2} \mathrm{H}_{6}$ & $\mathrm{Xe}$ & $\mathrm{SF}_{6}$ \\
\hline$\sigma(\AA)$ & 2.6 & 2.8 & 2.89 & 3.3 & 3.46 & 3.5 & 3.64 & 3.7 & 3.75 & 3.8 & 3.85 & 4.1 & 5.5 \\
\hline $\mathrm{T}_{\mathrm{c}}(\mathrm{K})$ & 5.3 & 44.5 & 33.2 & 304 & 155 & 151 & 126 & 209 & 283 & 191 & 306 & 290 & 319 \\
\hline
\end{tabular}

\section{Results and Discussion}

\subsection{Evolution of the CMS structure}

Although CMS materials formed from various polyimide precursors will exhibit differences in final structure and performance, the general features and concepts presented here should be relevant to all such precursors. For the specific case of the 6FDA:BPDA-DAM precursor of interest here, we will focus on the evolution from the random coil precursor during transformation into a disrupted plate structure with slit-like ultramicropores related to Fig. 1b in a typical pyrolysis protocol. Such a general protocol, noted in the experimental section, is represented in Fig. 3 with three distinct periods: ramp, soak, and cool. During these periods, the 
random polymer coil (Fig. 4-(i)) is transformed to a dramatically different CMS material. Elemental analysis of the CMS and consideration of evolved gases during the "ramp" phase of pyrolysis under UHP argon indicate that $\mathrm{CF}_{3} \mathrm{H}, \mathrm{HF}$ as well as $\mathrm{CO}_{2}, \mathrm{CO}$ and $\mathrm{H}_{2}$ are important components leaving during pyrolysis of such a precursor (29). During the temperature ramping process, further aromatization occurs, with considerable nitrogen maintained in the carbon until rather high temperatures (Table S-1), consistent with other studies (34-38). On the other hand, $\mathrm{CO}$ and $\mathrm{CO}_{2}$ evolution occurs even at relatively low temperatures to remove most, but not all, of the originally present oxygen atoms. For the precursor in Fig. 2, considering pathways consistent with the loss of the components mentioned above leads to a possible rigid, highly aromatic strand represented in Fig. 4-(ii), which will be used in discussion of the CMS formation. Details of the suggested strand structure are not crucial for high level considerations that are the main interest here, and this representative example strand will be discussed later.

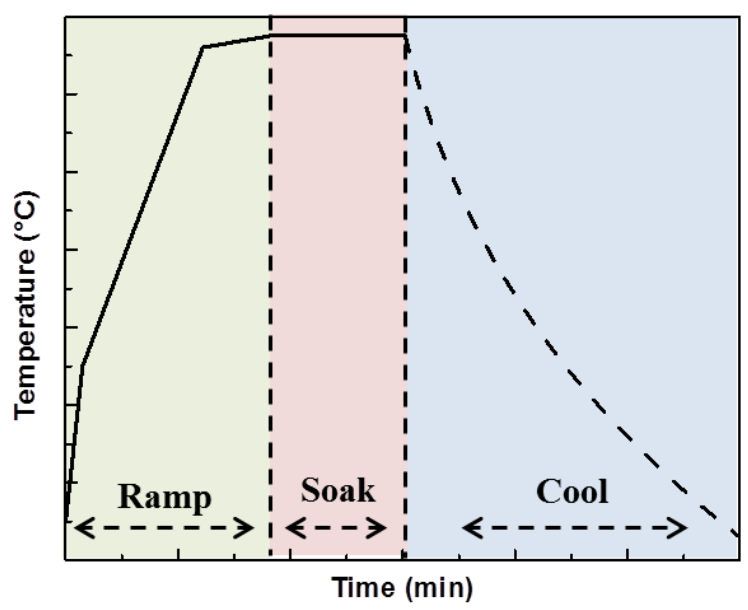

Figure 3.Typical time versus temperature profile used for CMS formation in this study.

Pyrolysis of a typical $\sim 150,000 \mathrm{~g} / \mathrm{mol}$ semi-flexible random coil polyimide, which loses only $\sim 40 \%$ of its weight upon pyrolysis, to produce a high molecular weight rigid structure presents a solid state packing problem. A similar problem is encountered in transforming a high 
molecular weight cellulosic precursor to the type of structure in Fig. 1b or 4-(vi). In either case, the entangled semi-flexible precursor undergoing aromatization and extreme linearization will tend to experience sufficient localized stresses to cause periodic scissions along its backbone, illustrated in Fig. 4-(i), (ii). Such backbone scissions are envisioned to occur during the temperature ramp to the final pyrolysis temperature (cf. Fig. 3 - "ramp") allowing aromatization to proceed while producing shorter, more mobile structural strands; however, a packing issue still exists for such rigid strand oligomers.

We envision that the rigid strands "solve the packing problem" in the way a rigid liquid crystalline polymer responds to the presence of high concentrations of rigid strands-by organizing into more packable entities such as plates(39). While counterintuitive, the aligned plates comprised of strands (Fig. 4-(iii)) are in an overall higher entropy state. Alignment of these strands during the temperature ramp phase of the pyrolysis is preferred as it reduces the excluded volume present within a "random" phase packing of strands (Fig. 4-(ii), allowing for an increased number of possible packing states of lateral entities. Some lateral linkages due to consolidation of lateral strands may occur, evolving molecular $\mathrm{H}_{2}$ in the process. Nevertheless, an amorphous nature results, since kinetic restrictions hinder perfect organization within the plates themselves and with imperfect long range stacking of plates during the limited time at high temperature during the "soak" phase in Fig. 3, when mobility is high. A typical idealized micropore "cell" with imperfectly packed sides comprised of imperfectly organized strands, reminiscent of Fig. 1b, is illustrated in Fig. 4-(iv). Ongoing evolution to the many neighboring cells in the idealized CMS structure is envisioned to occur during the final thermal soak and cooling after pyrolysis, as illustrated in Fig. 4-(iv) through Fig. 4-(vi). During the soak and cooling phases (cf. Fig. 3), adjacent micropore "cells" (Fig. 4-(iv)) will coalesce, wherein 
ultramicropore "walls" will be shared between "cells", resulting in a cellular structure envisioned to have a form similar to Fig. 4-(vi), where the front ultramicropore "walls" have been removed to highlight the resulting structure. The amorphous CMS, with micropores separated by ultramicropores in the micropore plate walls will, however, have molecular sieving properties. The hypothetical evolution path and structures illustrated in Fig. 4 is useful not only to envision the formation of the polyimide-derived CMS, but also to understand how controlling pyrolysis atmosphere and post-processing of CMS materials affect resulting membrane performance.

(i)

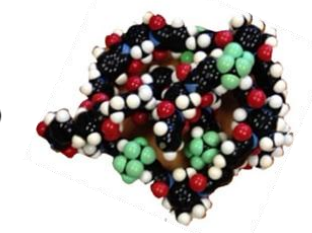

6FDA:BPDA-DAM precursor

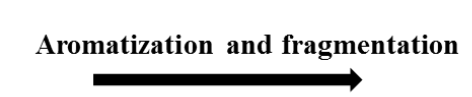

(Different ramp rates create different stresses and fragmentation)

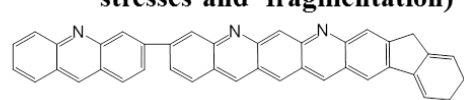

Entropy drives "plate" formation due to excluded volume effects
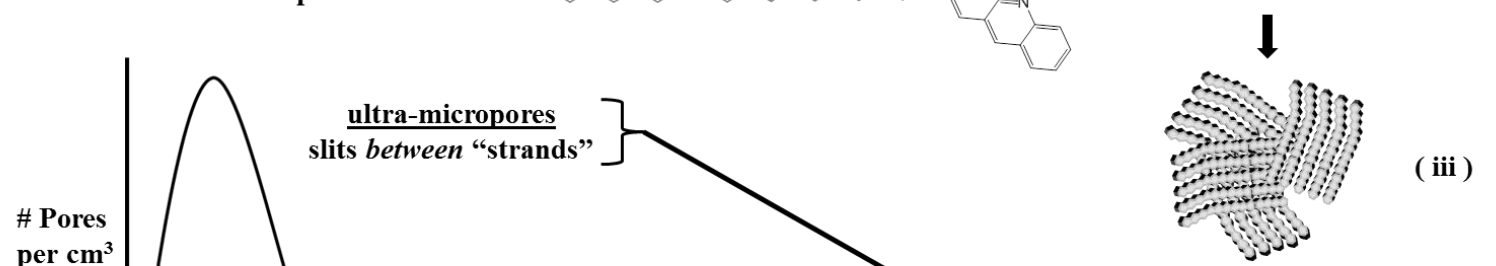
per $\mathrm{cm}^{3}$

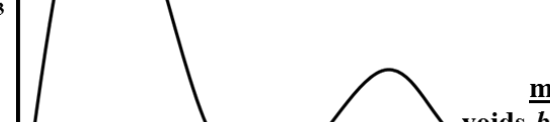

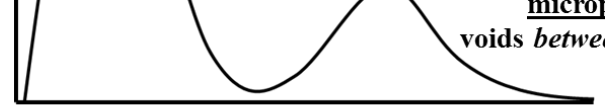

Pore Size $(\AA)$

( vi )

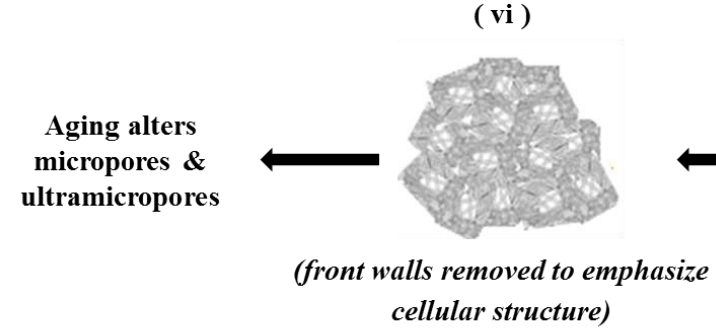

( v )

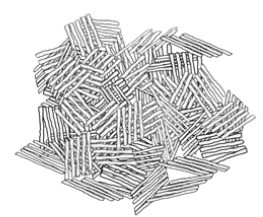

"Plates" organize during final ramp \& thermal soak lates"
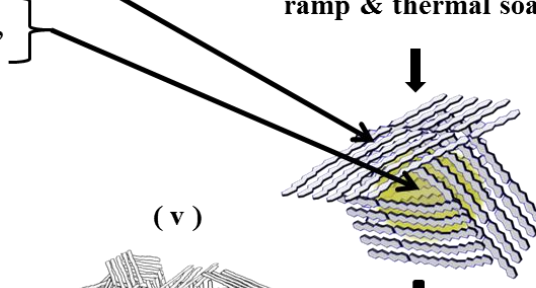

Figure 4. Envisioned initial steps in transformation from random coil precursor polyimide to organized amorphous CMS material with bimodal distribution of micropores with ultramicropores. 
Post-synthesis, CMS materials are subject to a physical aging phenomenon, where partial densification of the imperfectly stacked plates may occur, with reduction in the average distance between the plates, i.e. the micropore size or the molecular jump length ( $\lambda$ in Fig. 5a) (40-42). Such minor changes in organization of the aromatic strands within the various plates result in minor diffusion selectivity changes associated with the slits ( $\mathrm{d}_{\mathrm{um}}$ in Fig.5a) between the imperfectly organized strands, but with significant reductions in diffusion and sorption coefficients (40). The conceptual model presented in Figs. 4 \& 5 helps clarify how processing and structure can be related to resultant membrane performance in a consistent manner.

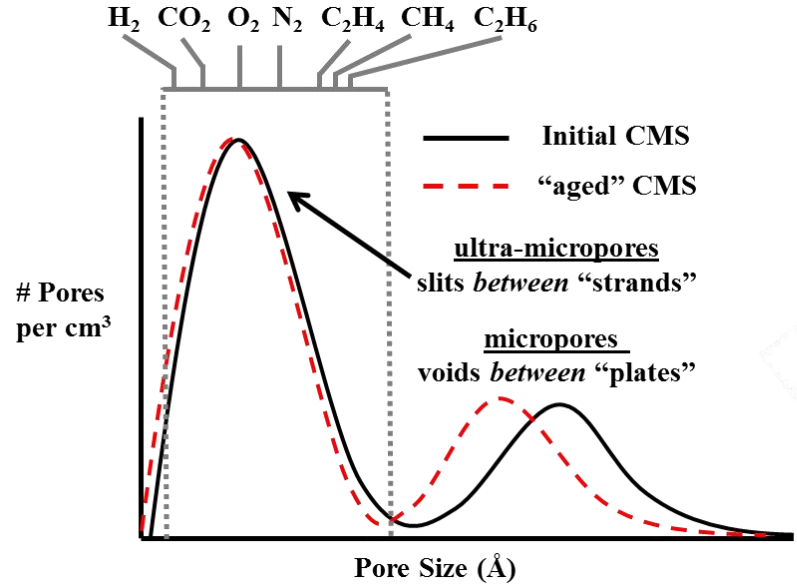

Pore Size ( $(\AA)$

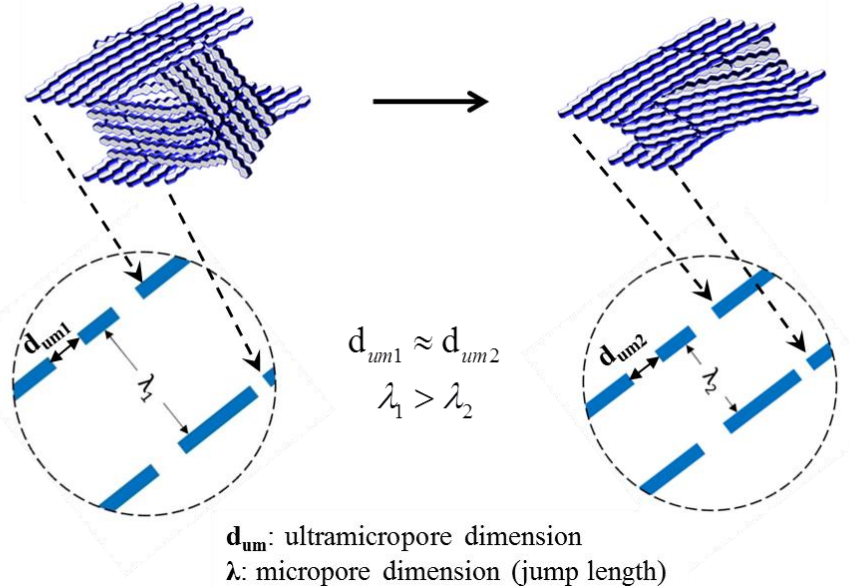

$\lambda$ : micropore dimension (jump length)

Figure 5a. Aging or annealing of CMS structure results in micropore settling with only minor ultramicropore slit tightening. 


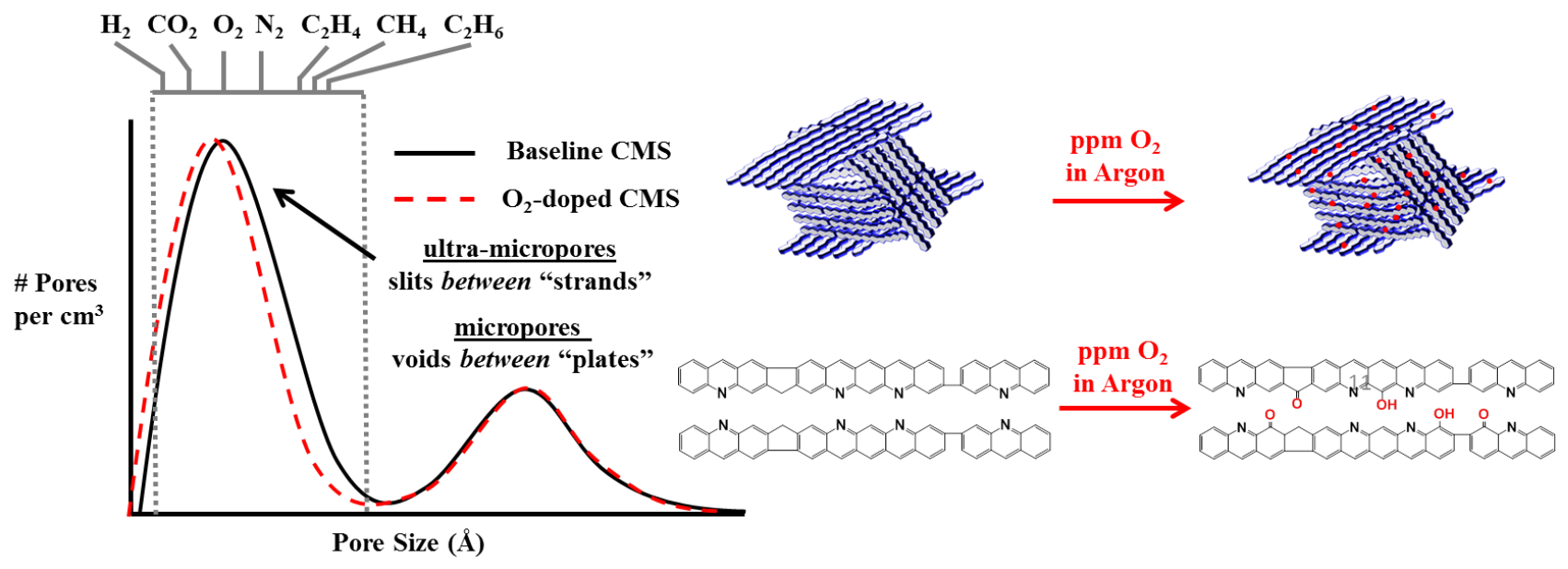

Figure 5b. Oxygen doping of CMS structure results in tightening of size-selective ultramicropores with no changes in micropore distribution.

During CMS formation, addition of parts per million of molecular oxygen into the pyrolysis atmosphere leads to selective functionalization of the edges of the imperfectly organized strands, illustrated by the idealized aromatic structure in Fig. 4-(ii) (43, 44). This doping can selectively narrow accessible points, and tighten the ultramicropore distribution as shown in Fig. 5b, resulting in an increase in membrane selectivity with a moderate reduction in productivity. Oxygen doping has been shown to only modify the size selective ultramicropores in Matrimid $^{\circledR}$ derived CMS materials, not the micropores believed to be responsible for sorption coefficients in Eqs. 1 and 7 (45). Another study demonstrated that for different 6FDA-based polyimide precursors the same effect applies, and presumably is general to all CMS materials (46). While determination of the exact state of the oxygen is outside the scope of this current discussion, spectroscopic evidence of carbonyls has been previously reported (43); however one can envision a multitude of oxygen chemisorption pathways during the complex pyrolysis process. In fact, as noted later, CMS formed under UHP Argon contains residual oxygen (Table S-1), which may be present in various states. For example, oxygen resulting in an alcohol 
functionality, whether remaining from precursor materials or due to oxygen doping, may undergo tautomerization to the previously observed carbonyl form $(47,48)$. Detailed identification of the array of oxygen functionalities in the CMS materials will clearly benefit from additional work in the future.

Finally, Figs. $4 \& 5$ also provide a framework to discuss changes in precursor structure and the impact on CMS separation properties. The biphenyl link in the BPDA unit in Fig. 2 provides a potential weak point in the precursor backbone, which actually offers a tool to control strand structure. Increasing the 6FDA:BPDA monomer ratio from (1:1) to (2:1) may impact the complex process of aromatization, fragmentation and organization envisioned in Fig. 4, along with and the ultimate CMS properties. The above conceptual framework will be used to discuss such issues in a self-consistent manner in the following sections.

\subsection{Impacts of Precursor Structure.}

\section{$\underline{\text { Sorption Isotherms and Pore Distribution Analysis from } \mathrm{CO}_{2}} \underline{\text { Sorption }}$}

Gas sorption measurements for the extensive array of gases in Table 1 were carried out on CMS derived from 6FDA:BPDA-DAM at $675{ }^{\circ} \mathrm{C}$. Newly measured sorption isotherms for 6FDA:BPDA-DAM at $35{ }^{\circ} \mathrm{C}$ are shown along with earlier reported results for Matrimid ${ }^{\circledR}$ derived CMS in Fig. 6 (17).

As described earlier, gas molecules sorb into micropore sites of the CMS and transport through the membrane by making diffusive jumps from one sorption site to the next through size selective ultramicropore slits. Gas sorption generally increases with condensability (e.g. critical temperature, $T_{\mathfrak{c}}$ ) but may also be augmented by other factors like dipoles and quadrupoles (49). Since micropore sorption sites communicate by narrower ultramicropore windows, exclusion of 
the larger penetrant in a gas pair can occur; however, the distribution of ultramicropore sizes makes complete exclusion unlikely. As expected, sorption isotherms in Fig. 6 show a general trend of increasing sorption uptake with increasing penetrant critical temperature (Table 1). Helium can sample most of the pores, but its sorption uptake is very small owing to its low critical temperature. On the other hand, $\mathrm{SF}_{6}$ with a high critical temperature and condensability shows low sorption uptake, presumably due to substantial molecular sieving because of its large size. For all gases, higher sorption is seen in 6FDA:BPDA-DAM derived CMS, compared to the corresponding Matrimid $^{\circledR}$ derived CMS reported earlier at $675{ }^{\circ} \mathrm{C}$, reflecting larger 6FDA:BPDA-DAM CMS micropore volume compared to Matrimid $^{\circledR}(17)$. 

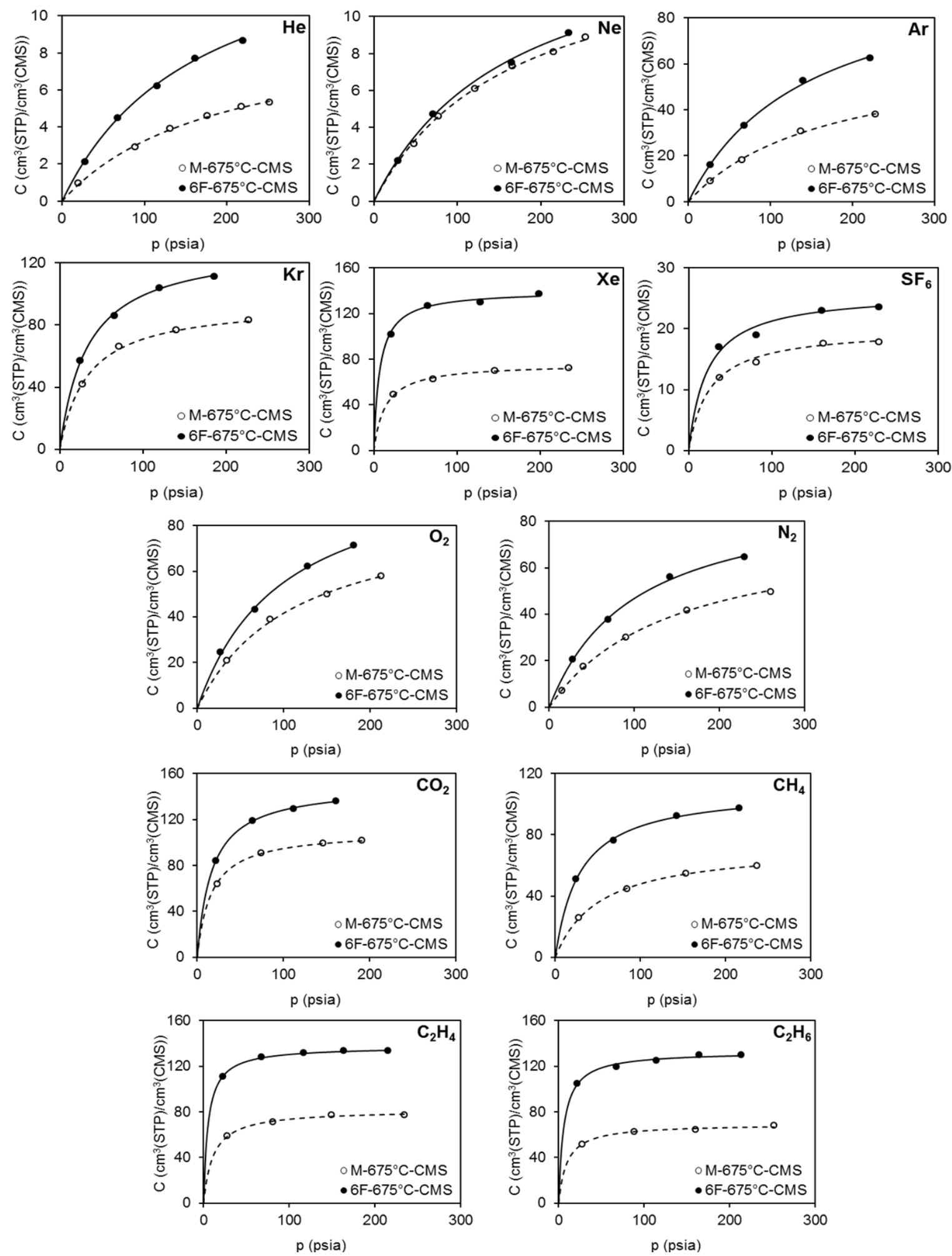

Figure 6. Sorption isotherms of different gases for CMS derived from UHP Ar pyrolysis of Matrimid ${ }^{\circledR}$ and 6FDA:BPDA-DAM at $675^{\circ} \mathrm{C}$. 


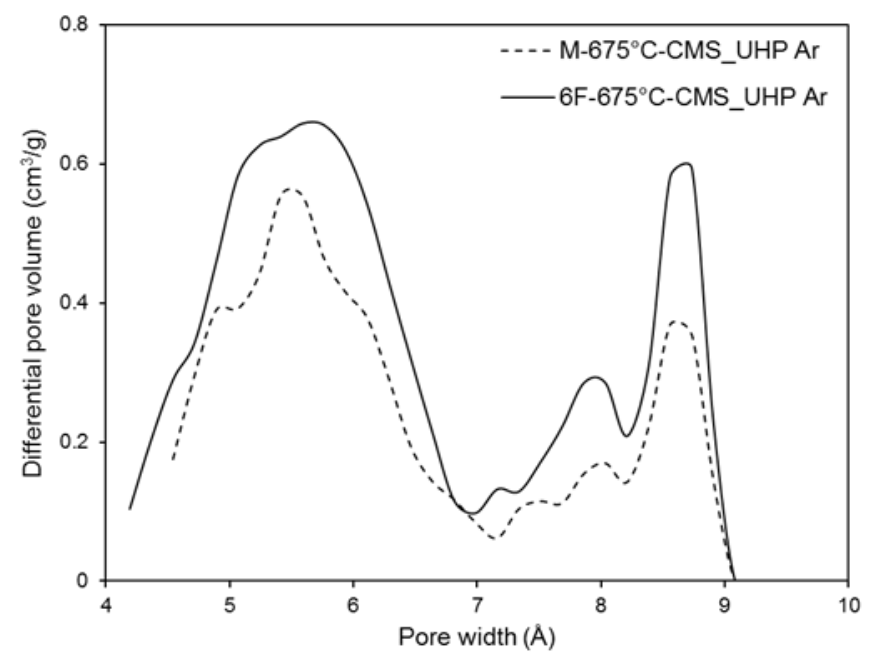

Figure 7. Pore size distribution from $\mathrm{CO}_{2}$ uptakes for CMS derived from UHP Ar pyrolysis of Matrimid $^{\circledR}(--)^{-}$and 6FDA:BPDA-DAM (--) at $675^{\circ} \mathrm{C}$. Data generated by Micromeritics for samples supplied from this work. Details in (1).

A similar trend was also reported by Kiyono et al. for CMS derived from Matrimid ${ }^{\circledR}$ and 6FDA:BPDA-DAM pyrolysis at $550{ }^{\circ} \mathrm{C}$ (43). A pore size distribution (Fig. 7), obtained from analysis of $\mathrm{CO}_{2}$ uptake measurements at $0{ }^{\circ} \mathrm{C}$, complement the above conventional sorption findings (1). Consistent with trends observed in in the sorption data for the wide range of gases in Fig. 6, the 6FDA:BPDA-DAM CMS has a larger overall micropore volume compared to Matrimid $^{\circledR}$ CMS reported earlier (1). The higher sorption uptakes of the 6FDA:BPDA-DAM derived CMS compared to the Matrimid $^{\circledR}$ derived CMS reflect higher saturation capacities, consistent with larger micropore volume when compared to Matrimid ${ }^{\circledR}$ noted in Fig. 7 and reported in Table S-2. The increased micropore volume is due to presence of the bulky $-\mathrm{CF}_{3}$ groups in the 6FDA unit of the 6FDA:BPDA-DAM precursor, which are evolved during the pyrolysis process as $\mathrm{HF}$ and $\mathrm{HCF}_{3}$, disrupting polymer chain packing. Loss of these bulky fluorinated groups leads to a more open CMS structure with higher porosity when compared to Matrimid $^{\circledR}$ which lacks any bulky fluorinated groups, and is reflected in the measurements 
above. Although useful for characterizing micropores, small ultramicropores with sizes $<4 \AA$ cannot be probed via $\mathrm{CO}_{2}$ or $\mathrm{N}_{2}$ sorption pore characterizations.

\section{Gas Diffusion as Ultramicropore Probes}

Permeability of the penetrant gases listed in Table 1 for CMS derived from the pyrolysis of Matrimid ${ }^{\circledR}$ and 6FDA:BPDA-DAM at $675^{\circ} \mathrm{C}$ are reported in Fig. 8. Permeability trends cannot be conclusively understood using pore size distributions obtained from sorption measurements; however diffusivity trends allow investigation of ultramicropore dimensions responsible for molecular sieving. The strong dependence of diffusivity upon molecular size is the basis for an effective "molecular ruler" to characterize the amorphous CMS materials, complementing traditional characterization methods (17). Examining diffusion coefficients and diffusion selectivities for various penetrant gas pairs can provide insight into CMS materials not captured in permeability and sorption measurements. Corresponding sorption and average transport diffusion coefficients (determined from $\mathrm{P} / \overline{\mathbb{S}}_{\mathrm{A}}$ using Eq. (1)) are reported in supplemental figures S-1 \& S-2, respectively.

For all gases, the 6FDA:BPDA-DAM-derived CMS shows higher permeabilities than Matrimid $^{\circledR}$ derived CMS. The higher permeabilities and free volume of the 6FDA:BPDA-DAM versus Matrimid $^{\circledR}$ polymer precursor correlates with higher permeabilities in the final CMS; however, as shown by Fu et. al. (22), such a correlation is not always seen. Given the complex events during the CMS formation, this lack of a simple correlation should not be surprising. 


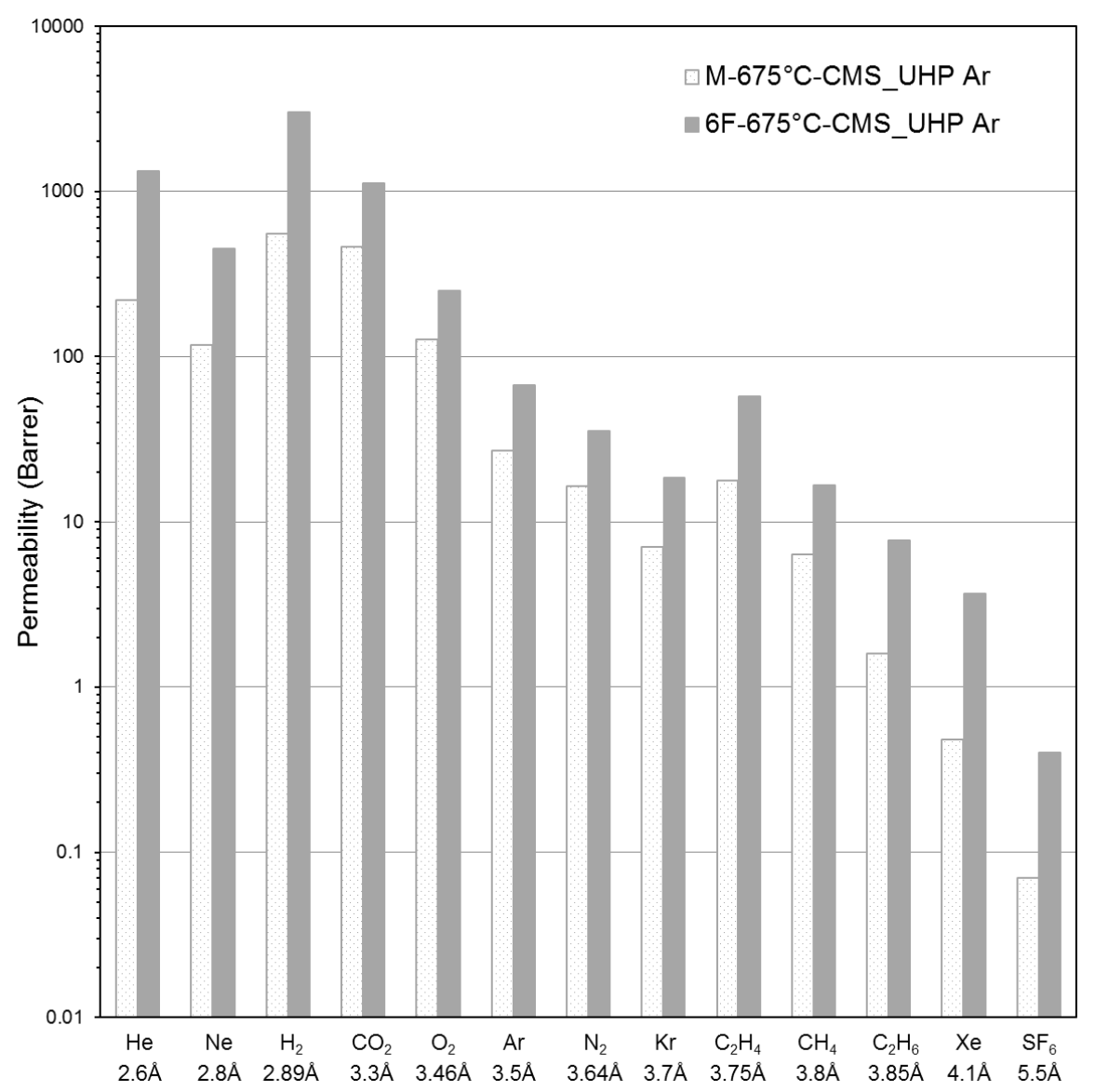

Figure 8. Permeabilities of different gases for CMS derived from Matrimid ${ }^{\circledR}$ and 6FDA:BPDADAM at $675{ }^{\circ} \mathrm{C}$ under UHP Argon. Permeability measurements were made at $35{ }^{\circ} \mathrm{C}$ using 50 psia feed pressure.

While permeability and sorption coefficients have practical utility; the special capability of CMS to execute penetrant size and shape selectivity is seen best by extracting and analyzing diffusion coefficients from permeability and solubility coefficients. The more meaningful thermodynamically corrected diffusivities in CMS derived from 6FDA:BPDA-DAM are shown in Fig. 9, along with values for previously studied Matrimid ${ }^{\circledR}$ derived CMS created at $675{ }^{0} \mathrm{C}$ under UHP Argon (17). These thermodynamically corrected coefficients are preferred here, since they avoid complications with concentration dependence of diffusion for highly condensable 
gases, and depend exclusively on penetrant shape and size. As expected, the corrected diffusion coefficients decrease by orders of magnitude with small differences in penetrant size. The diffusivities for all gases are much larger for the 6FDA:BPDA-DAM derived CMS compared to the Matrimid ${ }^{\circledR}$ derived CMS. Although ultramicropore windows are the diffusion limiting pores in CMS, the squared jump length in Eq. (8) also enters into the effective diffusion coefficient:

$$
\mathrm{D}_{\mathrm{A}}=f_{\mathrm{A}} \lambda_{\mathrm{A}}^{2} / 6
$$

where $f_{A}$ and $\lambda_{\mathrm{A}}$ are the random walk jumping frequency, and jump length, respectively (50). For a given CMS type, an average jump, $\lambda \sim \mathrm{d}_{\lambda}$ in Fig. 1a, applies. In the context of the idealized models in Fig. 1 and $4, \mathrm{~d}_{\lambda}$ corresponds to the average distance between the walls in an average micropore, such as shown in Fig. 4-(iv). The larger pore volumes at each effective size in 6FDA:BPDA-DAM-derived CMS compared to Matrimid ${ }^{\circledR}$ derived CMS in Fig. 6 suggests larger average values of $\lambda \sim \mathrm{d}_{\lambda}$ (cf. Fig. 1a) in 6FDA:BPDA-DAM derived CMS. This is due to presence of the bulky $-\mathrm{CF}_{3}$ groups in the 6FDA unit of 6FDA:BPDA-DAM precursor, which disrupt polymer chain packing leading to a more open CMS structure after pyrolysis. This feature contributes to higher diffusion and sorption coefficients-and hence much higher permeabilities. The ratio of thermodynamically-corrected diffusivities, measures the relative jump frequency for members of a gas pair in each of the two CMS types. In all cases, these data show higher selectivities when considering a given gas pair in Matrimid ${ }^{\circledR}$ derived CMS, reflecting a more compact organization of the corresponding ultramicropores comprising the walls of the respective micropores. While these trends hold in general, understanding subtle differences in ultramicropore distributions of CMS membranes derived from different polymer precursors is essential to engineering CMS for specific gas separations. Two of the most 
important cases, $\mathrm{CO}_{2} / \mathrm{CH}_{4}$ and $\mathrm{C}_{2} \mathrm{H}_{4} / \mathrm{C}_{2} \mathrm{H}_{6}$ will be considered further to illustrate some principles and the utility of the framework provided by Figs. 1, 4 and 5 .

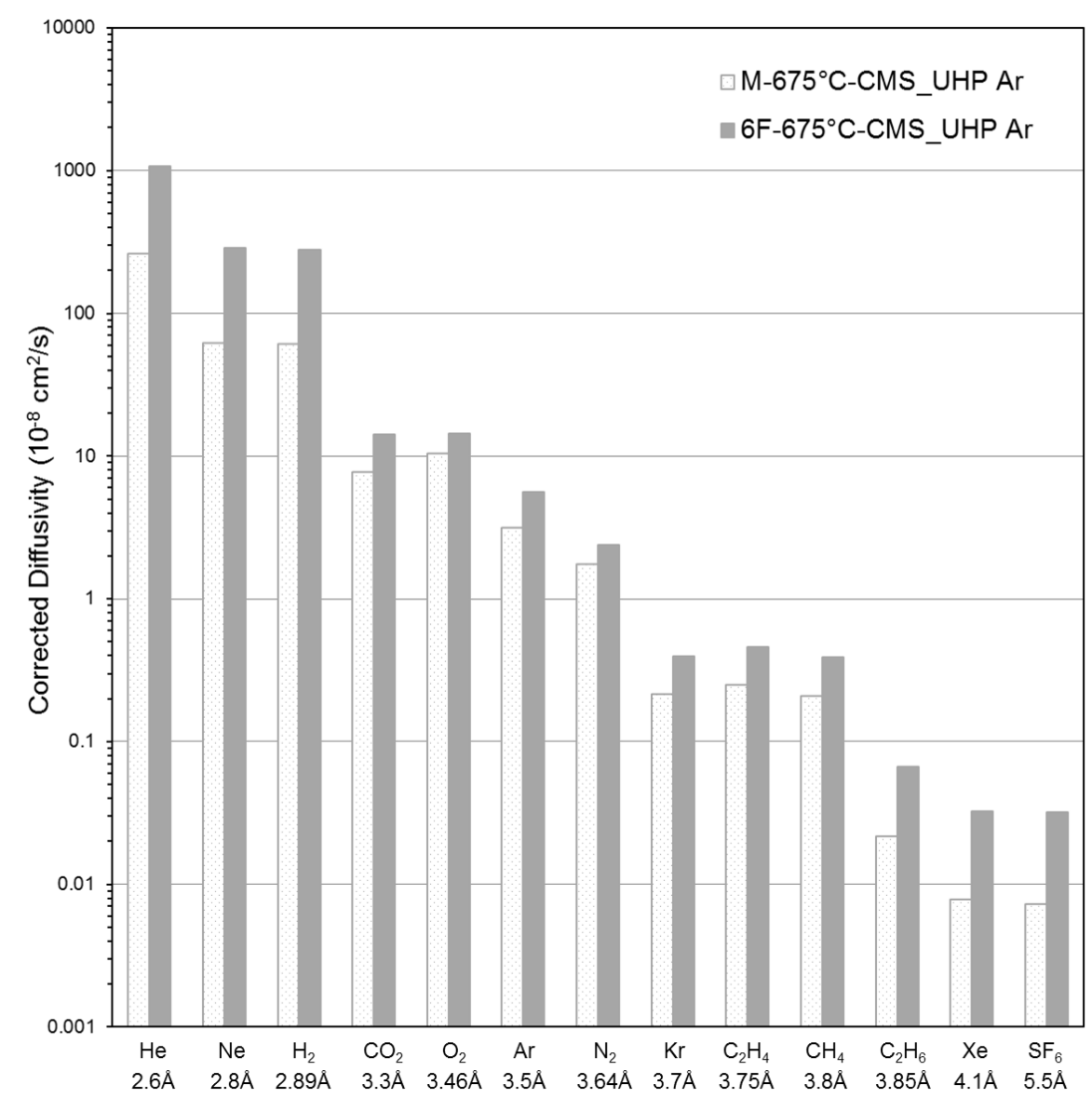

Figure 9. Corrected diffusivities of different gases at $35^{\circ} \mathrm{C}$ for CMS derived from UHP Argon Pyrolysis of Matrimid ${ }^{\circledR}$ and 6FDA:BPDA-DAM to $675^{\circ} \mathrm{C}$.

Considering the $\mathrm{CO}_{2} / \mathrm{CH}_{4}$ separation, the $\mathrm{CO}_{2}$ permeability of the $6 \mathrm{FDA}$ :BPDA-DAM derived CMS is approximately $230 \%$ higher than that of the Matrimid ${ }^{\circledR}$ derived CMS (due to combined higher $\mathrm{CO}_{2}$ diffusion and sorption effects). Despite this large productivity advantage for the 6FDA:BPDA-DAM CMS over the Matrimid ${ }^{\circledR} \mathrm{CMS}$, the $\mathrm{CO}_{2} / \mathrm{CH}_{4}$ diffusion selectivity (shown in Table 2) is quite similar for both materials. From this perspective, considering 6FDA:BPDA-DAM CMS over Matrimid ${ }^{\circledR} \mathrm{CMS}$ for $\mathrm{CO}_{2} / \mathrm{CH}_{4}$ separations is more desirable. In 
addition, this allows the 6FDA:BPDA-DAM CMS to be tuned to improve its $\mathrm{CO}_{2} / \mathrm{CH}_{4}$ selectivity even further while maintaining attractive permeability.

The technologically important $\mathrm{C}_{2} \mathrm{H}_{4} / \mathrm{C}_{2} \mathrm{H}_{6}$ pair is even more challenging to separate than the $\mathrm{CO}_{2} / \mathrm{CH}_{4}$ pair. Due to similarity in critical temperatures and size of these gases (Table 1), both sorption selectivity and diffusion selectivity of the $\mathrm{C}_{2} \mathrm{H}_{4} / \mathrm{C}_{2} \mathrm{H}_{6}$ pair tend to be low, thereby suppressing permselectivity (51-53). This pair is also particularly interesting, since it allows insights related to two relatively large penetrants with sizes at the higher size tail end of the ultramicropore pore size distribution illustrated in Fig. 4. Considering CMS formed at $675{ }^{\circ} \mathrm{C}$ under UHP Argon, the $\mathrm{C}_{2} \mathrm{H}_{4}$ permeability of the 6FDA:BPDA-DAM CMS is approximately $320 \%$ higher than that of the Matrimid ${ }^{\circledR}$ CMS; however, the diffusion selectivity is $54 \%$ lower

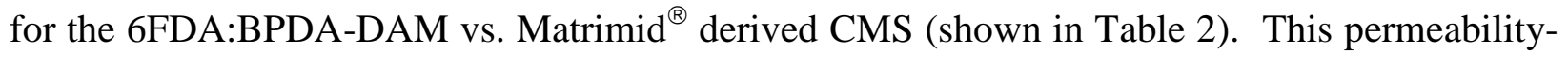
selectivity trade-off is especially apparent when considering the $\mathrm{C}_{2} \mathrm{H}_{4} / \mathrm{C}_{2} \mathrm{H}_{6}$ pair, and additional tools for tuning the selectivity without considerable permeability reductions become even more important.

Table 2. Corrected diffusion coefficients and diffusional selectivity properties of key gas pairs for Matrimid ${ }^{\circledR}$ and 6FDA:BPDA-DAM(1:1) CMS pyrolyzed to $675^{\circ} \mathrm{C}$ under UHP Argon.

\begin{tabular}{|c|c|c|c|c|c|}
\hline \multirow{2}{*}{ Gas } & \multirow{2}{*}{$\sigma(\AA)$} & \multicolumn{2}{|c|}{ Matrimid $^{\circledR}$} & \multicolumn{2}{c|}{ 6FDA:BPDA-DAM(1:1) } \\
\cline { 3 - 6 } & & $\mathbf{Ð}\left(\mathbf{c m}^{2} / \mathbf{s}\right)$ & $\boldsymbol{\alpha}_{\mathbf{D}}$ & $\mathbf{Ð}\left(\mathbf{c m}^{2} / \mathbf{s}\right)$ & $\boldsymbol{\alpha}_{\mathbf{D}}$ \\
\hline $\mathrm{CO}_{2}$ & 3.30 & $7.7 \mathrm{E}-08$ & $\mathrm{CO}_{2} / \mathrm{CH}_{4}=38.5$ & $13.5 \mathrm{E}-08$ & $\mathrm{CO}_{2} / \mathrm{CH}_{4}=35.0$ \\
\hline $\mathrm{C}_{2} \mathrm{H}_{4}$ & 3.75 & $2.5 \mathrm{E}-09$ & $\mathrm{C}_{2} \mathrm{H}_{4} / \mathrm{C}_{2} \mathrm{H}_{6}=12.3$ & $4.5 \mathrm{E}-09$ & $\mathrm{C}_{2} \mathrm{H}_{4} / \mathrm{C}_{2} \mathrm{H}_{6}=5.7$ \\
\hline
\end{tabular}

An additional topic on the impacts of precursor polymer structure relates to the 6FDA:BPDA-DAM(1:1) precursor shown in Fig. 2 with awareness that the BPDA component provides a potential weak point in the precursor backbone. In this regard, increasing the 
6FDA:BPDA monomer ratio from $(1: 1)$ to $(2: 1)$ tends to reduce backbone scissions in the stressed structure during aromatization. Larger, less mobile strands may suppress packing arrangement and lead to larger micropore volume and longer jump lengths in the (2:1) CMS variant. At the same time, after losing the $\mathrm{CF}_{3} \mathrm{H}$ groups, a more linear strand structure in the 6FDA:BPDA (2:1) case will have less degrees of freedom of movement due to fewer biphenyl bonds in the aromatized strand. This second factor could provide an intrinsically tighter, more selective ultramicropore size distribution. For instance, when considering the $\mathrm{CO}_{2} / \mathrm{CH}_{4}$ pair, our preliminary work is consistent with these two aforementioned effects and interpretable in terms of higher micropore volume and longer jump lengths with tighter and a more size and shape selective ultramicropore distribution for the $2: 1$ variant. Specifically, the $675^{\circ} \mathrm{C}$ pyrolyzed CMS 6FDA:BPDA-DAM(1:1) derived CMS gives 1100 Barrers $\mathrm{CO}_{2}$ permeability and permselectivity $\mathrm{CO}_{2} / \mathrm{CH}_{4}=66$, while the CMS from the precursor 6FDA:BPDA-DAM(2:1) gave 2800 Barrers $\mathrm{CO}_{2}$ permeability with selectivity $\mathrm{CO}_{2} / \mathrm{CH}_{4}=77$.

\subsection{Additional Pore Size Tuning Tools.}

\section{Oxygen Doping}

As described in the previous section, the similar diffusion selectivity between CMS derived from Matrimid ${ }^{\circledR}$ and 6FDA:BPDA-DAM (cf. Table 2) provides a major opportunity for tuning for the later material. Specifically, the productivity advantage of the 6FDA:BPDA-DAM derived CMS can be leveraged by further controlled tightening of the ultramicropores to sacrifice some permeability to create a more selective membrane. This strategy, illustrated in Fig. 10 by careful ultramicropore tuning via oxygen doping, results in moderate reductions in $\mathrm{CO}_{2}$ permeability with significant selectivity increases (43). Consistent with the representation in Fig. 
$5 b$, oxygen doping of the ultramicropore edges improves diffusion selectivity while maintaining large $\lambda \sim \mathrm{d}_{\lambda}$ that results in high diffusivity, and high micropore sorption capacity, so permeability also remains high. In the context of Fig. 5, oxygen doping primarily affects size selective ultramicropores rather than affecting the sorption coefficients in Eqs. 1 and 7. These oxygen doping results support the idea that modification of only the size selective ultramicropores can lead to a membrane material with both attractive selectivity and permeability. Although Fig. 10 relates to $550{ }^{\circ} \mathrm{C}$ pyrolysis, the same approach could clearly be applied for the $675{ }^{\circ} \mathrm{C}$ pyrolysis conditions to further augment performance of the 6FDA:BPDA-DAM(2:1) CMS even beyond the appealing preliminary results noted for this case.

This ultrafine pore size engineering can also be extended to even more challenging gas pairs, for instance the $\mathrm{C}_{2} \mathrm{H}_{4} / \mathrm{C}_{2} \mathrm{H}_{6}$ pair which differ only by $0.1 \AA$ in effective size (Table 1 ). Preliminary oxygen doping shows a remarkable effect for 6FDA:BPDA-DAM(1:1) for pyrolysis, with an optimum of $10 \mathrm{ppm} \mathrm{O}_{2}$ in Argon at $675^{\circ} \mathrm{C}$, versus UHP Argon at $675^{\circ} \mathrm{C}$. Specifically, the permselectivity was raised more than $30 \%$ from 7.3 in Fig. 8 to 9.6, with only moderate reduction of $30 \%$ in the attractive permeability under the $10 \mathrm{ppm} \mathrm{O}_{2}$ in Argon versus UHP Argon at $675^{\circ} \mathrm{C}$. Additional detailed studies of oxygen doping for this and other challenging gas pairs are currently underway. 


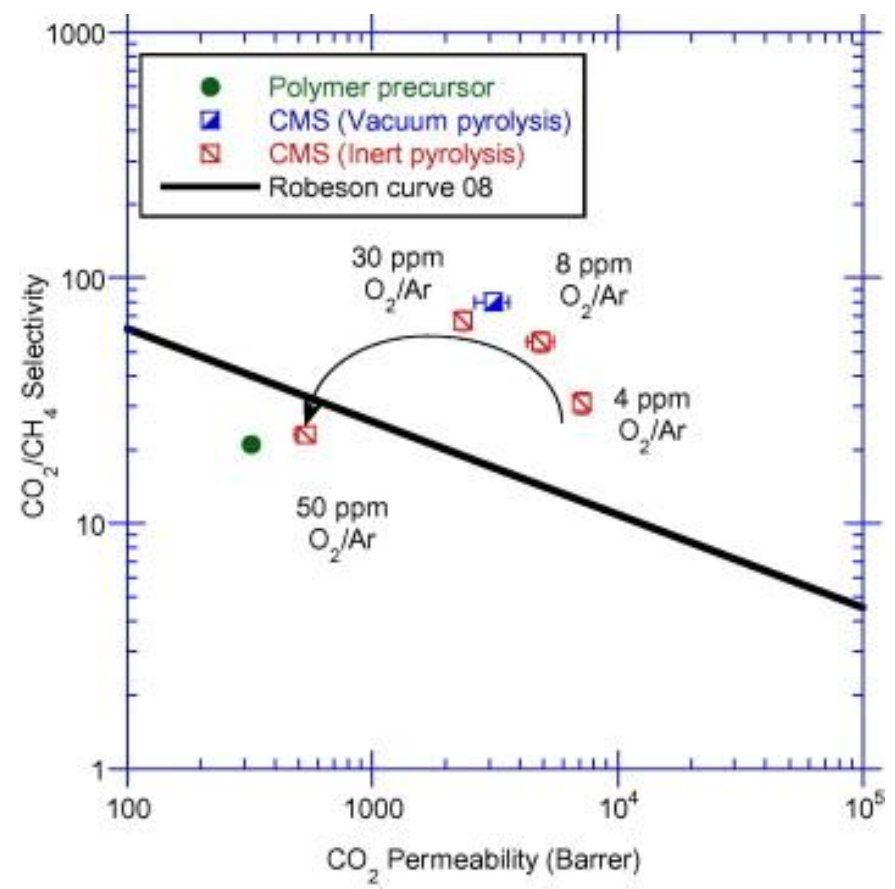

Figure 10. Separation performance of oxygen-doped 6FDA:BPDA-DAM(1:1) CMS films, pyrolyzed to $550{ }^{\circ} \mathrm{C}$. Reprinted with permission from reference (43). Copyright 2010 Elsevier.

\section{Amine Doping}

The upper end of the CMS ultramicropore size distribution and the lower end of the micropore distribution (cf. Figs. $4 \& 5$ ) reflect morphological features that control separation of larger penetrants in the upper size range of Table 1. This terrain ideally allows diffusion jumps by more compact large penetrants without losing size and shape selectivity relative to slightly less compact large penetrants. Pore tuning in this range, therefore, provides additional insight into the complex domain in Fig. 1, 4, and 5 comprising large ultramicropores and small micropores as morphologically distinct entities, which is considered next. A small number of poorly packed strands within intercommunicating micropore walls should comprise the upper range of the ultramicropore distribution. On the other hand, local regions with more "settled" plates having small values of $\lambda \sim \mathrm{d}_{\lambda}$ in Eq. (8) will comprise the lower range of the micropore 
distribution. In fact, the largest ultramicropores may effectively comprise defects in packing associated with the chaotic drive towards ordered plates, which may not be so neatly organized as the idealized representation in Fig. 4. Indeed, the actual CMS composition (Table S-1), while envisioned to comprise mostly $\mathrm{C}, \mathrm{H}$, and $\mathrm{N}$, with structures illustrated in Fig. 4, also includes some oxygen even when formed under UHP Argon. Although speculative, we envision naturally occurring, residual oxygen-containing sites to be associated with such regions of less perfection created during the chaotic scission and organization process.

These residual oxygen-containing sites may provide a route for selective functionalization of the CMS membranes with carefully selected "dopants", sharpening the upper ultramicropore and lower micropore size distributions illustrated in Fig. 4. This observation motivated recent work (41), exploiting this fact as an extension of the more conventional oxygen doping concept, noted earlier in Fig. 5b. As shown in Fig. 11a, addition of small molecule dopants are envisioned to functionalize the larger slits resulting from imperfect packing of strands in the CMS structure. In the context of Fig. 11, treatment of conventionally-produced CMS was doped with trace amounts (1000 - $10 \mathrm{ppm})$ of paraphenylene diamine (PPDA) in tetrahydrofuran (THF) (41). While a wide array of molecular dopants can be envisioned, utilization of diamines in this preliminary study was based on the fact that small amine penetrants introduced to the CMS are tenaciously, even covalently retained (54). This preliminary work was done on identical asymmetric CMS membranes with the same thin dense layer formed at $550^{\circ} \mathrm{C}$, so productivity is reported in GPU $\left(1 \mathrm{GPU}=10^{-6} \mathrm{cc}(\mathrm{STP}) / \mathrm{cm}^{2} \mathrm{cmHg}\right)$. 


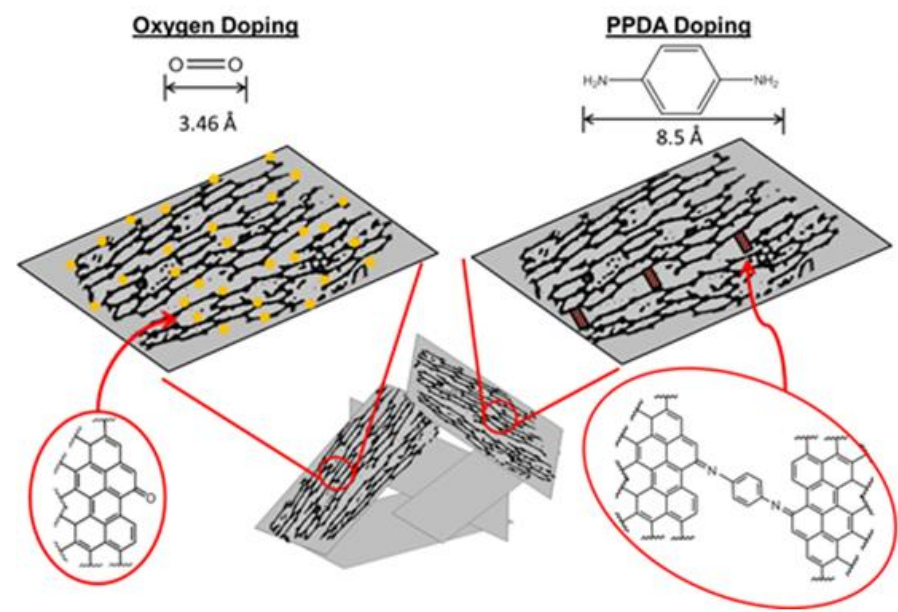

(a)

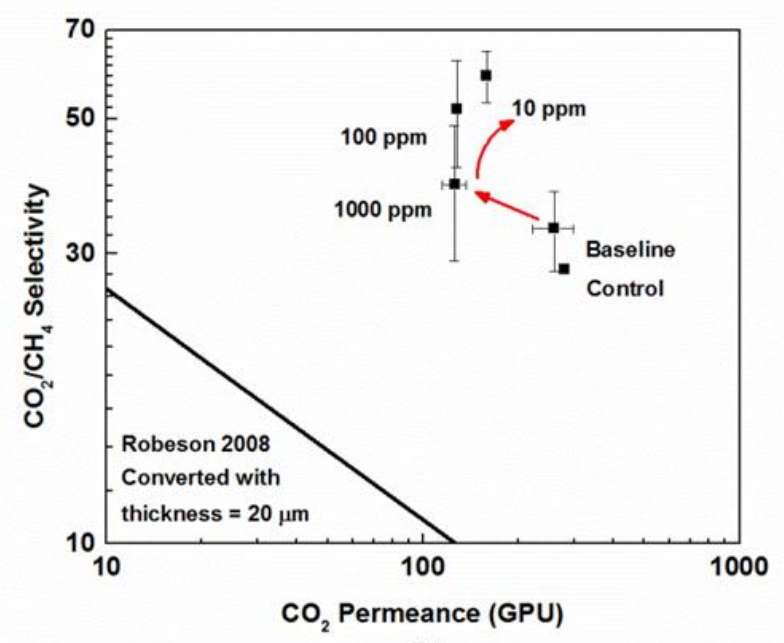

(b)

Figure 11. (a) Comparison of oxygen and "amine doping" techniques. (b) Performance of amine doped 6FDA:BPDA-DAM CMS membranes for $\mathrm{CO}_{2} / \mathrm{CH}_{4}$ separation. Reprinted with permission from reference (41). Copyright 2016 Wiley.

The lower pyrolysis temperature, compared to $675^{\circ} \mathrm{C}$, was chosen to maintain larger micropore dimensions (cf. Fig 5a) to provide high sorption capacity $\left(\mathrm{C}_{\mathrm{H}}^{\prime}\right)$ and diffusion jump lengths $\left(\mathrm{d}_{\lambda}\right.$ in Fig. 1a-i). The provocative trends in Fig. 11b suggest that amines may be suited to sharpen the large end of the ultramicropore range to complement oxygen doping for the small and mid-range ultramicropores. Combining these two ultramicropore engineering tools will provide abilities to refine CMS for such larger penetrants such as the olefin-paraffin pairs, as well as smaller ones in Fig. 5 and Table 1.

\section{Conclusions}

Differences in CMS structure and performance resulting from the use of different polymer precursors, while keeping other pyrolysis conditions fixed, were discussed. Sorption uptake measurements were used to characterize the CMS micropore distribution. A gas probe method 
provided insight into changes in CMS transport properties in terms of differences in ultramicropore distributions, leading to changes in CMS performance. As with other studies, the relationship between precursor and ultimate CMS properties was shown to be more complex than one related only to precursor fractional free volume. The 6FDA:BPDA-DAM $675{ }^{\circ} \mathrm{C}$ CMS shows a higher $\mathrm{C}_{2} \mathrm{H}_{4}$ permeability but lower $\mathrm{C}_{2} \mathrm{H}_{4} / \mathrm{C}_{2} \mathrm{H}_{6}$ selectivity compared to the Matrimid ${ }^{\circledR}$ CMS. This general permeability-selectivity trade-off however may not always be obvious since in the case of $\mathrm{CO}_{2} / \mathrm{CH}_{4}$ separation, the $6 \mathrm{FDA}$ :BPDA-DAM CMS shows a comparable selectivity as the Matrimid ${ }^{\circledR}$ CMS, but with much higher permeability. This is especially important when the effects due to multiple pyrolysis parameters are coupled. For example, simply increasing the pyrolysis temperature may result in a CMS with higher selectivity but lower permeability as seen in going from pyrolysis of Matrimid ${ }^{\circledR}$ at $500{ }^{\circ} \mathrm{C}$ vs. $675^{\circ} \mathrm{C}$ (17). On the other hand changing the polymer precursor to 6FDA:BPDA-DAM while increasing the pyrolysis temperature at the same time may produce a more optimal CMS avoiding this unwanted trade-off, as was demonstrated for $\mathrm{CO}_{2} / \mathrm{CH}_{4}$ separation. Careful consideration of the $\mathrm{CMS}$ micropore and ultramicropore distributions is thus important for engineering CMS for a given gas separation application.

\section{Acknowledgements}

The authors thank The Dow Chemical Company and the Office of Basic Energy Science of the U.S. Department of Energy (DE-FG02-04ER15510) for financial support of this work. The authors especially thank Mark Brayden and Marcos Martinez for helpful discussions and comments. 


\section{References}

(1) Steel, K. M.; Koros, W. J. An investigation of the effects of pyrolysis parameters on gas separation properties of carbon materials. Carbon. 2005, 43, 1843-1856.

(2) Koresh, J. E.; Sofer, A. Molecular-sieve Carbon Permselective Membrane: 1. Presentation of New Device for Gas-Mixture Separation. Sep. Sci. Technol. 1983, 18, 723-734.

(3) Koresh, J. E.; Sofer, A. The Carbon Molecular-sieve Membranes: General Properties and Permeability of CH4/H2 Mixtures. Sep. Sci. Technol. 1987, 22, 973-982.

(4) Ma, X.; Swaidan, R.; Teng, B.; Tan, H.; Salinas, O.; Litwiller, E.; Han, Y.; Pinnau, I. Carbon molecular sieve gas separation membranes based on an intrinsically microporous polyimide precursor. Carbon. 2013, 62, 88-96.

(5) Ma, X.; Lin, B. K.; Wei, X.; Kniep, J.; Lin, Y. S. Gamma-Alumina Supported Carbon Molecular Sieve Membrane for Propylene / Propane Separation. Ind. Eng. Chem. Res. 2013, 52, 4297-4305.

(6) Kim, Y. K.; Park, H. B.; Lee, Y. M. Preparation and characterization of carbon molecular sieve membranes derived from BTDA-ODA polyimide and their gas separation properties. J. Memb. Sci. 2005, 255, 265-273.

(7) Robeson, L. M. Correlation of separation factor versus permeability for polymeric membranes. J. Memb. Sci. 1991, 62, 165-185.

(8) Robeson, L. M. The upper bound revisited. J. Memb. Sci. 2008, 320, 390-400.

(9) Freeman, B. D. Basis of Permeability/Selectivity Tradeoff Relations in Polymeric Gas Separation Membranes. Macromolecules 1999, 32, 375-380.

(10) Sanders, D. F.; Smith, Z. P.; Guo, R.; Robeson, L. M.; McGrath, J. E.; Paul, D. R.; Freeman, B. D. Energy-efficient polymeric gas separation membranes for a sustainable future: A review. Polymer. 2013, 54, 4729-4761.

(11) Rouqurol, J.; Avnir, D.; Fairbridge, C.; Everett, D.; Haynes, J.; Pernicone, N.; Ramsay, J.; Sing, K.; Unger, K. Recommendations for the characterization of porous solids. Pure Appl. Chem. 1994, 66, 1739-1758.

(12) Jenkins, G. M.; Kawamura, K. Polymeric Carbons -- Carbon Fibre, Glass and Char; Cambridge University Press, 1976.

(13) Mariwalat, R. K.; Foley, H. C. Evolution of Ultramicroporous Adsorptive Structure in Poly (furfuryl alcohol) - Derived Carbogenic Molecular Sieves. Ind. Eng. Chem. Res. 1994, 33, 607-615.

(14) Pierson, H. O. Handbook of carbon, graphite, diamond and fullerenes: Properties, Processing, and Applications; Noyes Publications: Park Ridge, NJ., 1993.

(15) Kim, Y. K.; Lee, J. M.; Park, H. B.; Lee, Y. M. The gas separation properties of carbon molecular sieve membranes derived from polyimides having carboxylic acid groups. $J$. Memb. Sci. 2004, 235, 139-146.

(16) Xiao, Y.; Chung, T.; Chng, M. L.; Tamai, S.; Yamaguchi, A. Structure and Properties Relationships for Aromatic Polyimides and Their Derived Carbon Membranes : Experimental and Simulation Approaches. J. Phys. Chem. B. 2005, 109, 18741-18748.

(17) Rungta, M.; Xu, L.; Koros, W. J. Structure-performance characterization for carbon molecular sieve membranes using molecular scale gas probes. Carbon. 2015, 85, 429442. 
(18) Fu, Y.-J.; Liao, K.-S.; Hu, C.-C.; Lee, K.-R.; Lai, J.-Y. Development and characterization of micropores in carbon molecular sieve membrane for gas separation. Microporous Mesoporous Mater. 2011, 143, 78-86.

(19) Park, H. B.; Kim, Y. K.; Lee, J. M.; Lee, S. Y.; Lee, Y. M. Relationship between chemical structure of aromatic polyimides and gas permeation properties of their carbon molecular sieve membranes. J. Memb. Sci. 2004, 229, 117-127.

(20) Campo, M. C.; Magalhães, F. D.; Mendes, A. Comparative study between a CMS membrane and a CMS adsorbent: Part I-Morphology, adsorption equilibrium and kinetics. J. Memb. Sci. 2010, 346, 15-25.

(21) Chen, J.; Loo, L. S.; Wang, K.; Do, D. D. The structural characterization of a CMS membrane using Ar sorption and permeation. J. Memb. Sci. 2009, 335, 1-4.

(22) Fu, S.; Sanders, E. S.; Kulkarni, S. S.; Koros, W. J. Carbon molecular sieve membrane structure-property relationships for four novel 6FDA based polyimide precursors. $J$. Memb. Sci. 2015, 487, 60-73.

(23) Suda, H.; Haraya, K. Gas Permeation through Micropores of Carbon Molecular Sieve Membranes Derived from Kapton Polyimide. J. Phys. Chem. B 1997, 101, 3988-3994.

(24) Saufi, S.; Ismail, A. Fabrication of Carbon Membranes for Gas Separation - a review. Carbon . 2004, 42, 241-259.

(25) Ruthven, D. M.; Karger, J. Diffusion in Zeolites and Other Microporous Solids; Wiley \& Sons: New York, NY, 1992.

(26) Breck, D. W. Zeolite Molecular Sieves: Structure, Chemistry, and Use; Wiley \& Sons: New York, NY, 1974.

(27) Ruthven, D. M.; Reyes, S. C. Adsorptive separation of light olefins from paraffins. Microporous Mesoporous Mater. 2007, 104, 59-66.

(28) Rungta, M. Carbon Molecular Dense Film Membranes for Ethylene/Ethane Separations. Atlanta GA USA, Georgia Institute of Technology, PhD Thesis, 2012.

(29) Williams, P. J. Analysis of Factors Influencing The Performance of CMS Membranes for Gas Separations. Altanta GA USA, Georgia Institute of Technology, PhD Thesis, 2006.

(30) Xu, L.; Rungta, M.; Koros, W. J. Matrimid® derived carbon molecular sieve hollow fiber membranes for ethylene/ethane separation. J. Memb. Sci. 2011, 380, 138-147.

(31) Reid, R. C.; Prausnitz, J. M.; Sherwood, T. K. The Properties of Gases and Liquids; 3rd ed.; McGraw-Hill: New York, NY, 1977.

(32) Bird, R. B.; Stewart, W. E.; Lightfoot, E. N. Transport Phenomena; 2nd ed.; John Wiley and Sons: New York, NY, 2002.

(33) Rungta, M.; Zhang, C.; Xu, L.; Koros, W. J. Membrane-Based Ethylene/Ethane Separation: The Upper Bound and Beyond. AIChE J. 2013, 59, 3475-3489.

(34) Hatori, H.; Yamada, Y.; Shiraishi, M.; Yoshihara, M.; Kimura, T. The mechanism of polyimide pyrolysis in the early stage. Carbon. 1996, 34, 201-208.

(35) Inagaki, M.; Harada, S.; Sato, T.; Nakajima, T.; Horino, Y.; Morita, K. Carbonization of polyimide film "Kapton." Carbon. 1989, 27, 253-257.

(36) Bürger, A.; Fitzer, E.; Heym, M.; Terwiesch, B. Polyimides as precursors for artificial carbon. Carbon. 1975, 13, 149-157.

(37) Ehlers, G. F. L.; Fisch, I. R.; Powell, W. R. Thermal Degradation of Polymers with Phenylene Units in the Chain . IV . Aromatic Polyamides. J. Polym. Sci. Part A Polym. Chem. 1970, 8, 3511-3527. 
(38) Turk, M. J.; Ansari, A. S.; Alston, W. B.; Gahn, G. S.; Frimer, A. A.; Scheiman, D. A. Evaluation of the thermal oxidative stability of polyimides via TGA techniques. J. Polym. Sci. Part A Polym. Chem. 1999, 37, 3943-3956.

(39) Flory, P. J. Molecular Theory of Liquid Crystals. Adv. Polym. Sci. 1984, 59, 1-36.

(40) Xu, L.; Rungta, M.; Hessler, J. V.; Qiu, W.; Brayden, M.; Martinez, M.; Barbay, G.; Koros, W. J. Physical aging in carbon molecular sieve membranes. Carbon. 2014, 80, $155-166$.

(41) Wenz, G. B.; Koros, W. J. Tuning Carbon Molecular Sieves for Natural Gas Separations: A Diamine Approach. AIChE J. 2016. DOI: 10.1002/aic.15405.

(42) Ma, X.; Williams, S.; Wei, X.; Kniep, J.; Lin, Y. S. Propylene/Propane Mixture Separation Characteristics and Stability of Carbon Molecular Sieve Membranes. Ind. Eng. Chem. Res. 2015, 54, 9824-9831.

(43) Kiyono, M.; Williams, P. J.; Koros, W. J. Effect of polymer precursors on carbon molecular sieve structure and separation performance properties. Carbon. 2010, 48, 44324441.

(44) Grisdale, R. O. The Properties of Carbon Contacts. J. Appl. Phys. 1953, 24, 1288.

(45) Kiyono, M. Carbon Molecular Sieve Membranes For Natural Gas Separations. Atlanta GA USA, Georgia Institute of Technology, PhD Thesis, 2010.

(46) Fu, S.; Wenz, G. B.; Sanders, E. S.; Kulkarni, S. S.; Qiu, W.; Ma, C.; Koros, W. J. Effects of pyrolysis conditions on gas separation properties of 6FDA/DETDA:DABA(3:2) derived carbon molecular sieve membranes. J. Memb. Sci. 2016, 520, 699-711.

(47) Kandambeth, S.; Mallick, A.; Lukose, B.; Mane, M. V.; Heine, T.; Banerjee, R. Construction of crystalline 2D covalent organic frameworks with remarkable chemical (Acid/Base) stability via a combined reversible and irreversible route. J. Am. Chem. Soc. 2012, 134, 19524-19527.

(48) Roberts, J. D.; Caserio, M. C. Basic Principles of Organic Chemistry; W. A. Benjamin, Inc.: New York, NY, 1965.

(49) Mukaddam, M.; Litwiller, E.; Pinnau, I. Gas Sorption, Diffusion, and Permeation in Nafion. Macromolecules 2016, 49, 280-286.

(50) Petropoulos, J. H. Some fundamental approaches to membrane gas permeability and permselectivity. J. Memb. Sci. 1990, 53, 229-258.

(51) Tanaka, K.; Taguchi, A.; Hao, J.; Kita, H.; Okamoto, K. Permeation and separation properties of polyimide membranes to olefins and paraffins. J. Memb. Sci. 1996, 121, 197-207.

(52) Salinas, O.; Ma, X.; Litwiller, E.; Pinnau, I. Ethylene/ethane permeation, diffusion and gas sorption properties of carbon molecular sieve membranes derived from the prototype ladder polymer of intrinsic microporosity (PIM-1). J. Memb. Sci. 2016, 504, 133-140.

(53) Salinas, O.; Ma, X.; Litwiller, E.; Pinnau, I. High-performance carbon molecular sieve membranes for ethylene/ethane separation derived from an intrinsically microporous polyimide. J. Memb. Sci. 2016, 500, 115-123.

(54) Jones, C. W.; Koros, W. J. Carbon molecular sieve gas separation membranes-II. Regeneration following organic exposure. Carbon. 1994, 32, 1427-1432. 

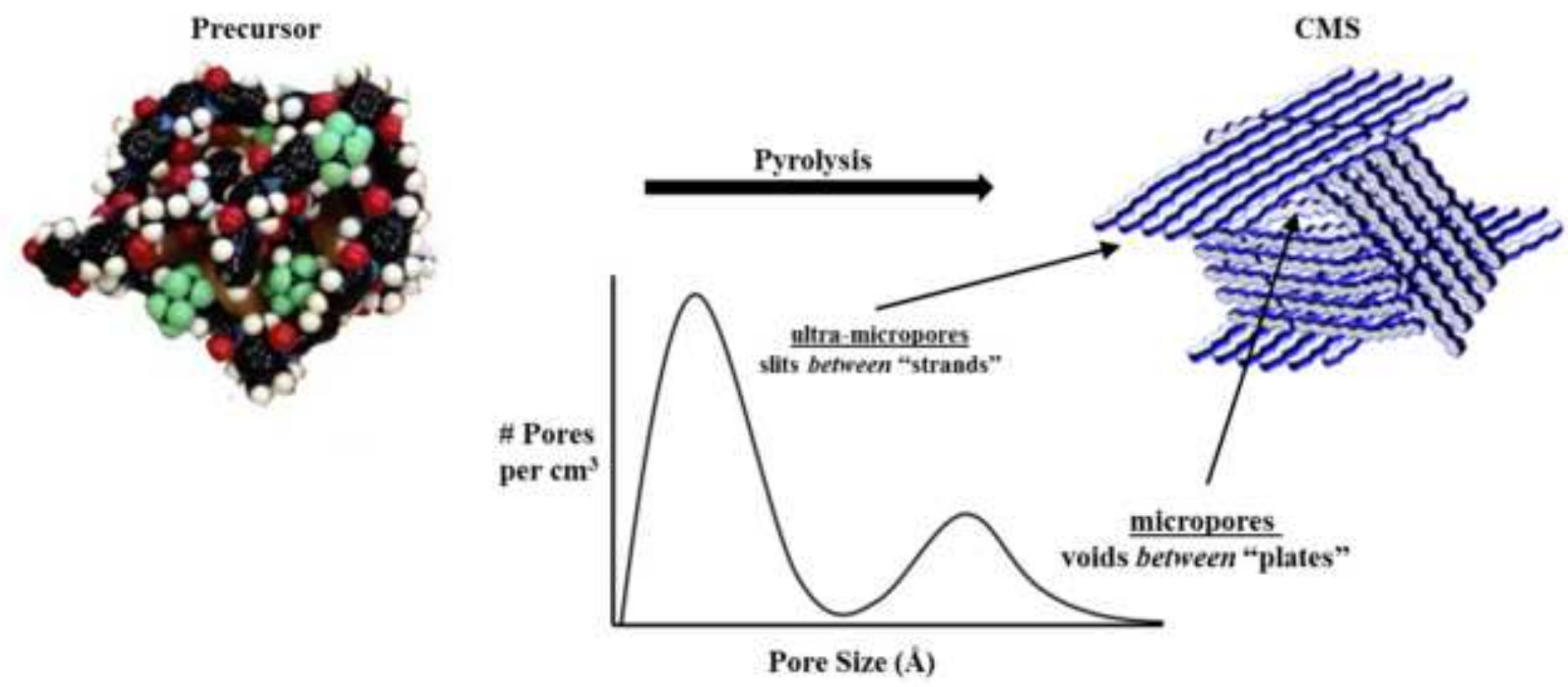